\title{
Quality of Root Canal Filling Using a Bioceramic Sealer in Oval Canals: A Three-Dimensional Analysis
}

\author{
Poliana J. Penha da Silva ${ }^{1}$ Marília F. Marceliano-Alves ${ }^{2}$ José C. Provenzano ${ }^{2}$ Rafaela L. A. Dellazari \\ Lucio Souza Gonçalves ${ }^{1}$ Flávio R. F. Alves²
}

${ }^{1}$ Department of Endodontics, Estácio de Sá University, Rio de Janeiro, RJ, Brasil

2Department of Endodontics, Iguaçu University, Nova Iguacu, Brazil

Eur J Dent 2021;15:475-480

\begin{abstract}
Address for correspondence Marília F. Marceliano-Alves, DDS, MSc, $\mathrm{PhD}$, Department of Endodontics and Dental Research, Avenue Abílio Augusto Távora, 2134, Nova Iguaçu-RJ 26260-045, Brazil (e-mail: mmarceliano@hotmail.com).
\end{abstract}

\begin{abstract}
Keywords

- bioceramic sealers

- EndoSequence BC sealer

- root canal filling

- single-cone technique

Objectives The oval canals may be associated with inadequate debridement, which can affect the quality of the root canal filling, thus the treatment outcome. The aim of the present work was to compare the quality of oval canals fillings using EndoSequence $\mathrm{BC}$ sealer with the single-cone technique or cold lateral compaction.

Materials and Methods Thirty-eight human single-rooted premolars with oval canals were instrumented to $1 \mathrm{~mm}$ from the apical foramen with hand nickel-titanium files, followed by circumferential filing with Hedstrom files. Teeth were paired into two groups based on their micro-computed tomography (CT) morphological parameters. Both groups were filled using EndoSequence $B C$ sealer. The first used a single cone and the other with the cold lateral compaction technique. The voids volume was evaluated by micro-CT and the percentage was calculated for the total length and for the apical $5 \mathrm{~mm}$ of each canal. The Mann-Whitney $U$ test was used to assess whether the surface area and obturation length differed significantly between the groups and to compare the percentage of voids for each technique.

Results Both techniques resulted in less than $16 \%$ voids, with no statistically significant difference between them for the total canal length and for the apical $5 \mathrm{~mm}$ $(p>0.05)$.

Conclusions The quality of the obturation performed with the single-cone technique was similar to that achieved with lateral compaction using EndoSequence BC sealer in oval canals.
\end{abstract}

\section{Introduction}

The main goals of root canal obturation are to maintain the disinfection achieved through chemomechanical preparation and to prevent percolation of periradicular exudate or oral fluids into the root canal system, ensuring a biologically favorable environment conducive to tissue repair. ${ }^{1}$

published online

February 3, 2021
DOI https://doi.org/

10.1055/s-0040-1722095

ISSN 1305-7456.
Inadequate root canal fillings are strongly correlated with short-term and long-term endodontic treatment failures. ${ }^{2}$ Moreover, voids may serve as breeding sites for the proliferation of microorganisms that resisted the chemomechanical preparation or were able to reach the root canal system secondarily. ${ }^{3}$ Therefore, the quality of endodontic obturation is crucial to maintain treatment success.
(C) 2021. European Journal of Dentistry.

This is an open access article published by Thieme under the terms of the Creative Commons Attribution-NonDerivative-NonCommercial-License, permitting copying and reproduction so long as the original work is given appropriate credit. Contents may not be used for commercial purposes, or adapted, remixed, transformed or built upon. (https://creativecommons.org/licenses/by-nc-nd/4.0/). Thieme Medical and Scientific Publishers Pvt. Ltd. A-12, 2nd Floor, Sector 2, Noida-201301 UP, India 
After ISO standardization of endodontic instruments in the 1960s, clinicians started to perform obturations using a gutta-percha single cone technique, silver or titanium made cones in combination with traditional sealers. However, soon thereafter, evidence that this technique was not satisfactory for oval canals emerged. The larger amount of sealer required to fill oval canals resulted in a large area of shrinkage, with subsequent formation of voids between the filling material and the root canal wall. ${ }^{4}$ Consequently, fluid leakage and sealer degradation were frequent. ${ }^{5}$ For this reason, the term "single-cone technique" was associated with poor quality obturations for many years.

In the last decade, with the advent of bioceramic sealers with low contraction rates ${ }^{6,7}$ and the introduction of single-file systems combined with matching gutta-percha points, the former practice of obturating canals with a single cone has resumed. With these new sealers, the role of the gutta-percha point is solely to act as a vehicle and to allow potential retreatment, since material is not a sealer per se, but rather, the filling material. Simplicity of use, speed of treatment, and lighter pressure on the root canal walls are the main advantages of this technique.

EndoSequence BC sealer (Brasseler USA; Savannah, GA; also marketed as TotalFill BC Sealer in other countries) has stood out among these new sealers. A recent study evaluated the clinical outcomes of non-surgical root canal treatment with EndoSequence BC sealer, reporting a success rate of $90.9 \%{ }^{8}$ The favorable properties of this material include antibacterial action, ${ }^{9}$ biocompatibility, ${ }^{10}$ adequate seal, ${ }^{11}$ and adhesion to dentin. ${ }^{12}$ An earlier study revealed that EndoSequence $\mathrm{BC}$ sealer undergoes slight expansion, whereas traditional sealers such as AH Plus and Pulp Canal Sealer undergo shrinkage. ${ }^{7}$ As a calcium phosphate silicate-based sealer, EndoSequence BC sealer forms hydroxyapatite in the presence of water, which leads to a direct bond between sealer and dentin. ${ }^{13}$ The manufacturer of EndoSequence BC sealer recommend the single-cone technique using an EndoSequence $\mathrm{BC}$ point, which is made from gutta-percha impregnated and coated with bioceramic nanoparticles. According to the manufacturer, this technique results in a root canal filling free of gaps, and that facilitates retreatment, when necessary.

Obturation of oval root canals has always been challenging in comparison with root canals with a circular cross-section. The irregular shape of oval canals is associated with inadequate debridement, which can negatively affect the quality of the root canal filling. ${ }^{14}$ For this reason, concerns regarding the obturation of oval root canals with the single-cone technique are still valid, even when using bioceramic sealers. Thus, the aim of this study was to compare the quality of obturations of oval root canals using EndoSequence BC sealer with the single-cone technique or cold lateral compaction. Micro-CT images were used to evaluate the volume of voids in the obturations.

\section{Materials and Methods}

\section{Sample Selection and Initial Micro-CT Analysis}

The teeth used in the present study were obtained from the Institutional Tooth Bank, and the Ethics Committee approved the study protocol. According to the sample size calculation, 17 teeth per group would be sufficient to show a 5\% discrepancy in the percentage of voids, with statistical power of $80 \%$.

Initially, 210 maxillary and mandibular premolars extracted for reasons unrelated to this study were selected. Only teeth with completely formed apices, apical patency, no evidence of external resorption, and with a single straight canal were selected. Further selection was based on radiographs taken with buccolingual and mesiodistal directions. Teeth with constricted or calcified canals, internal resorption, prior endodontic treatment, or evidence of presenting two canals were excluded. A total of 96 teeth fulfilled these criteria. Selected teeth were stored at $37^{\circ} \mathrm{C}$ at $100 \%$ humidity until the next steps.

After achieving coronal access with high-speed watercooled diamond burs, the crowns were separated from the roots at the cementum-dentin junction. The teeth were decoronated to achieve a similar root length for all specimens and create a plateau to keep them in a perpendicular position during micro-CT scanning. Roots were then scanned in a SkyScan 1174 v2 micro-CT scanner (Bruker-MicroCT, Kontich, Belgium) using a $50 \mathrm{kV}$ X-ray unit operating under an $800 \mathrm{~mA}$ current. The scanning parameters included a rotation step of 1.0 , a $180^{\circ}$ rotation, and $17-\mu \mathrm{m}$ pixel size. Images of each root specimen were reconstructed using the NRecon v.1.6.9 software (Bruker-MicroCT), which generated axial and transversal sections of the root's internal structure. Next, each root canal had its length measured from the top of the micro-CT image until the bottom using the CTAn software (Bruker-MicroCT). The measure was divided by three, determining the coronal, middle and apical thirds of the canal. Then, the major and minor horizontal diameters were obtained from the last apical slice of each third. If a root canal displayed oval cross-section (diameter ratio $>1.5: 1)^{15}$ in two out of the three thirds, it was classified as oval. Following the micro-CT exam, 38 roots with oval canals were selected for this study.

\section{Root Canal Preparation and Obturation}

The length of the root canal was obtained by inserting a 15 K-type file (Dentsply/Maillefer; Ballaigues, Switzerland) into the canal until its tip was visible at the apical foramen under a stereomicroscope with $10 \mathrm{X}$ magnification (Leica LED3000 NVI; Leica Microsystems Heerbrugg, St. Gallen, Switzerland). The total length of the canal was measured with a digital pachymeter and designated as the patency length.

All root canals were instrumented by the alternating rotation movements technique. ${ }^{16}$ The working length $(\mathrm{WL})$ was established $1 \mathrm{~mm}$ short of the apical foramen. The sequence of the root canal preparation included the following steps, in sequence: Gates-Glidden burs II, III, and IV were used to prepare the coronal two-thirds of the root canals in the radiograph tooth length subtracted of 5,7 , and $9 \mathrm{~mm}$, respectively; exploration with a $15 \mathrm{~K}$-file type instrument and radiography for canal length measurement; apical preparation until a K 50 file (Dentsply/Maillefer); 1-mm step-back with increments up to $4 \mathrm{~mm}$ short of the WL was performed; and circumferential filing with the aid of a size 50 Hedström file (three short filing motions were applied per root face). 
Abundant and frequent irrigation with $2.5 \% \mathrm{NaOCl}$ was performed throughout the preparation $(1 \mathrm{~mL}$ after each file change). Apical foramen patency was verified in all canals using a $15 \mathrm{~K}$-type file (Dentsply/Maillefer). After the preparation was completed, the smear layer was removed with $2 \mathrm{~mL}$ of $17 \%$ ethylenediaminetetraacetic acid for 1 minute, followed by $2 \mathrm{~mL}$ of $2.5 \% \mathrm{NaOCl}$ for 1 minute. Finally, canals were dried with size FM paper points (Dentsply / Maillefer).

Teeth were matched into two groups according to the micro-CT morphological parameters obtained prior to instrumentation: volume, surface area, structure model index (SMI), and root length ${ }^{17}$ ( - Fig. 1). One group was filled using EndoSequence $\mathrm{BC}$ sealer with the single-cone technique (BC-SC, $n=19$ ) and the other by cold lateral compaction (BC-LC, $n=19)$.

\section{Single-Cone Technique}

For group BC-SC, a small amount (1-2 reference markings of the EndoSequence BC sealer syringe) of EndoSequence BC sealer was gently dispensed into the canal to fill the coronal third. The sealer was carefully spread onto the canal walls up to the WL using a size $15 \mathrm{~K}$-type file (Dentsply/Maillefer). Then, a size 50.02 EndoSequence gutta-percha cone coated with a small amount of sealer was slowly inserted into the canal up to the WL. Following that, the gutta-percha cone was cut at the level of the cementodentinal junction with a heated carrier, and gentle vertical pressure was applied with compactors (1.1 mm diameter, Dentsply/Maillefer). This procedure was repeated twice to compact the gutta-percha into the coronal portion of the root canal.

\section{Cold Lateral Compaction}

For the BC-LC group, the EndoSequence BC sealer and a size 50.02 EndoSequence gutta-percha cone were inserted into the canal in the same manner as for group BC-SC. Following that, size FF accessory gutta-percha cones (Dentsply/Maillefer) were inserted into the canal until the spreader could not penetrate beyond the coronal third of the canal. Then, the gutta-percha cones were cut and compacted as for group BC-SC.

In both groups, the excess sealer was removed from the access cavity with a moist cotton pellet. A single operator performed all root canal obturations with both techniques.
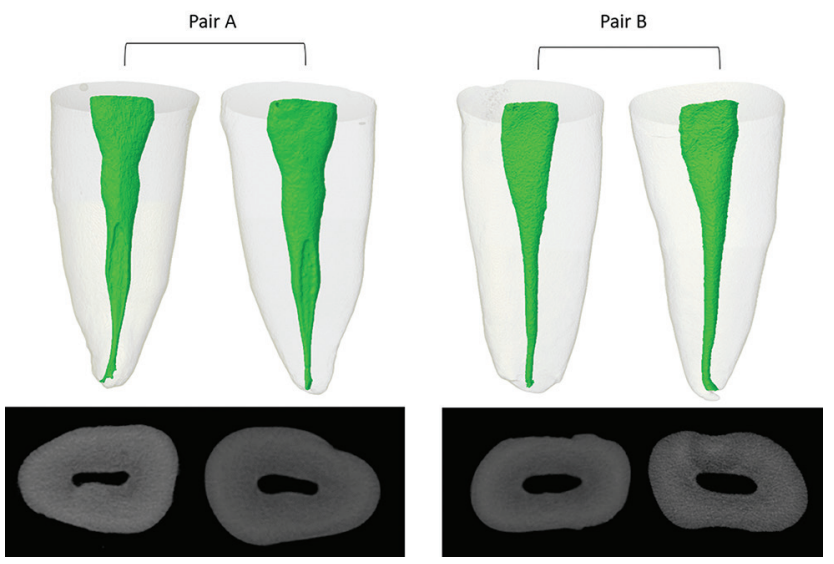

Fig. 1 Examples of tooth pairing.
The fit of the gutta-percha master cone was verified radiographically. No additional radiographs were taken to prevent operator bias during visual analysis. The obturated roots were stored at $100 \%$ moisture and $37^{\circ} \mathrm{C}$ for 10 days until the final setting. ${ }^{13}$

\section{Microtomographic Analysis of the Obturations}

After all canals were obturated, the roots were once again scanned by micro-CT using the same parameters described previously. All sections were reconstructed with the NRecon software (Bruker-MicroCT). The length of the root canal obturations was measured in millimeters using the CTAn v.1.14.4 software (Bruker-MicroCT). Images were converted to NRRD file format using the Image J $1.50 \mathrm{~d}$ software (National Institutes of Health, Bethesda, Maryland, United States). Subsequently, the images were captured using the 3D Slicer v1.5.1.2 software (www.slicer.org, MIT Artificial Intelligence Laboratory, Brigham \& Women's Hospital Surgical Planning Laboratory, and Harvard Medical School, Massachusetts, United States). Voids were quantified by subtraction of the models before and after root canal obturation was completed. The volume of the voids was measured using the Image J software (National Institutes of Health). Finally, three-dimensional models were generated with the CTAn v.1.14.4 software (Bruker-MicroCT) and visualized in the CTVol v.2.3.1 software (Bruker-MicroCT) (-Fig. 2). After that, the percentage of voids in relation to the

\section{BC-SC}
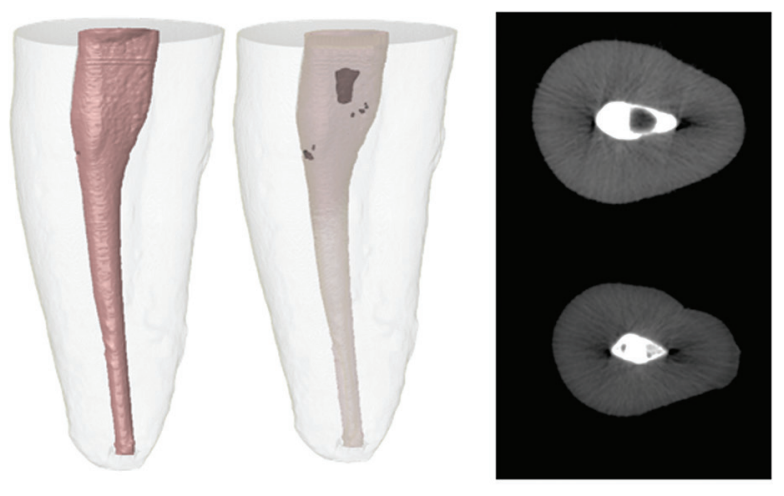

BC-LC
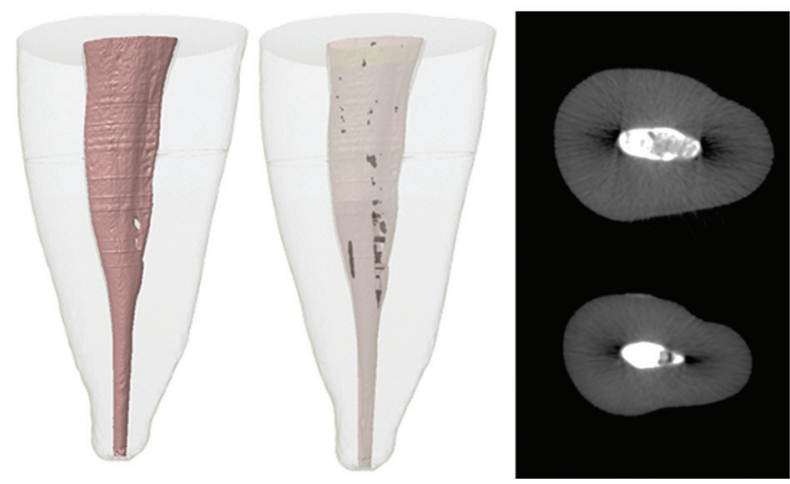

Fig. 2 Micro-computed tomography analysis of voids: EndoSequence $B C$ sealer with the single cone technique (BC-SC) and $B C$ sealer with the cold lateral compaction (BC-LC). 
volume of the prepared canal was calculated for each tooth at the evaluated levels.

\section{Statistical Analysis}

Data normality was assessed using the Shapiro-Wilk test. The Mann-Whitney $U$ test was used to assess whether the surface area, root length, and obturation length differed significantly between the two groups and to compare the percentage of voids for each technique, considering the volume of the prepared canal (volume of the obturation mass plus the volume of the voids). The independent $t$-test was used to compare the initial canal volume and the model index (SMI). This analysis was performed for two segments of the canal: $10 \mathrm{~mm}$ (hereafter referred to as the total canal length) and apical $5 \mathrm{~mm}$. Statistical analyses were performed using the SPSS software, version 17.0 (SPSS Inc.; Chicago, Illinois, United States), at a significance level of $5 \%$.

\section{Results}

The micro-CT morphological parameters obtained before instrumentation did not differ between groups ( $p>0.05$ ). The obturation length was similar for the two groups $(p>$ 0.05). The means were 15.77 and $15.97 \mathrm{~mm}$, for BC-SC and BC-LC groups, respectively, demonstrating that this variable was controlled in the present study. No statistically significant difference was found in the percentage of voids in the obturations performed with either technique, considering the levels evaluated $(p>0.05)$. Analyzing the total canal length, the mean volume of voids was $1.36 \mathrm{~mm}^{3}$ (median, $1.30 \mathrm{~mm}^{3}$; range, $0.03-3.11 \mathrm{~mm}^{3}$ ) and $1.28 \mathrm{~mm}^{3}$ (median, $0.84 \mathrm{~mm}^{3}$; range, $0-3.98 \mathrm{~mm}^{3}$ ) for BC-SC and BC-LC, respectively. Conversely, for the apical portion the means were $0.43 \mathrm{~mm}^{3}$ (median, $0.29 \mathrm{~mm}^{3}$; range, 0.01-1.19 $\mathrm{mm}^{3}$ ) and $0.21 \mathrm{~mm}^{3}$ (median, $0.07 \mathrm{~mm}^{3}$; range, $0-0.70 \mathrm{~mm}^{3}$ ) for BC-SC and $\mathrm{BC}-\mathrm{LC}$, respectively. Both techniques presented less than $16 \%$ of voids. In all specimens where voids were detected, the volume was greater in the coronal part of the canal (-Table 1, -Figs. 2 and 3). Voids were not detected in some canals from the BC-LC group ( 3 in the full canal length and 6 in the apical $5 \mathrm{~mm})$.

\section{Discussion}

Over 30 years ago, the clinical outcomes of the single-cone technique were compared with cold lateral compaction, with results favoring the latter technique. At that time, the success rate of the single-cone technique was $88.4 \%$, while lateral compaction had a success rate of $91.8 \%{ }^{18}$ However, most sealers used at that time were zinc oxide and eugenol-based. Therefore, the solubility and contraction of those sealers are likely to have negatively affected the outcomes of obturations performed with the single-cone technique, which requires a greater amount of sealer. ${ }^{19}$

The present study used a three-dimensional microtomographic analysis to evaluate the quality of filling of oval canals with the single-cone technique or the cold lateral compaction using EndoSequence $\mathrm{BC}$ sealer. The decision to use EndoSequence BC sealer instead of other bioceramic sealers was based on recent evidence of favorable results when this material was used with a single cone (success rate of $90.9 \%$ after follow-up for at least 1 year). ${ }^{8}$ This recent study contrasts with Seltzer's (1988) ${ }^{18}$ and demonstrates the positive impact of this new sealer on the success rate of the single-cone technique.

In the present study, no differences were found between the two obturation techniques regarding the quality of the obturation. Thus, our results favor the single-cone technique due to its greater simplicity, ease, quickness, and reproducibility compared with lateral compaction. ${ }^{19}$ Some properties of the EndoSequence BC sealer may explain why the single-cone technique resulted in obturations with the same quality as those performed by lateral compaction: this sealer's good adhesiveness to the dentin walls ${ }^{20}$ and flowability $^{21}$ have been previously reported. Furthermore, the formation of hydroxyapatite when using this sealer may be responsible for its chemical bond to dentin. ${ }^{22}$

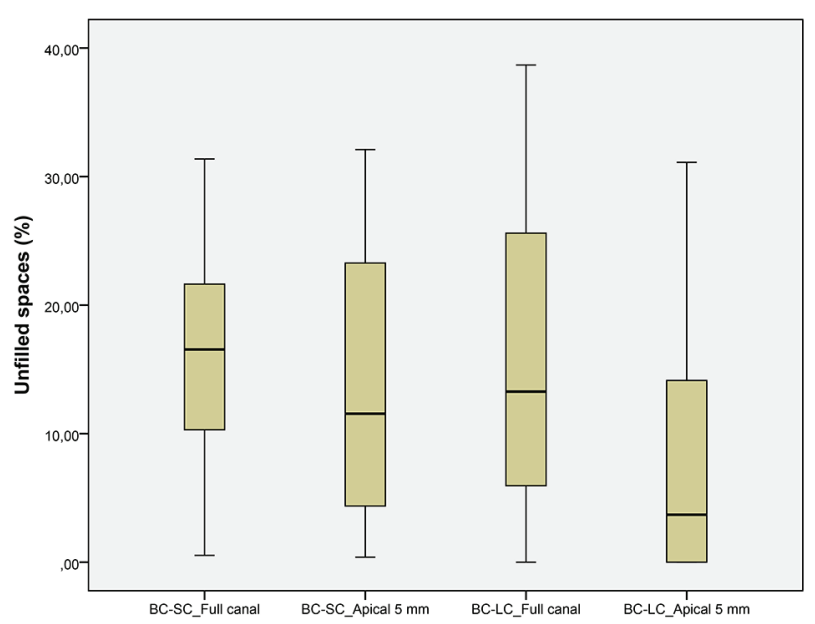

Fig. 3 Box plot representing the percentage of voids in each group, for each segment evaluated (total canal length or apical $5 \mathrm{~mm}$ ).

Table 1 Percentage of voids in relation to the volume of the prepared canal, in each group

\begin{tabular}{|l|l|l|l|l|l|}
\hline Group & Segment & $\boldsymbol{n}$ & Mean \pm SD & Median & Range \\
\hline \multirow{3}{*}{ BC-SC } & Full canal & 19 & $15.20 \pm 8.54$ & 16.55 & $0.53-31.37$ \\
\cline { 2 - 6 } & Apical 5 mm & 19 & $13.11 \pm 10.75$ & 11.55 & $0.39-32.10$ \\
\hline \multirow{2}{*}{ BC-LC } & Full canal & 19 & $15.24 \pm 12.21$ & 13.27 & $0-38.68$ \\
\cline { 2 - 6 } & Apical 5 mm & 19 & $8.44 \pm 10.21$ & 3.69 & $0-31.11$ \\
\hline
\end{tabular}

Abbreviation: SD, standard deviation. 
Although the physicochemical properties of EndoSequence BC sealer have been fully investigated, ${ }^{23}$ no previous studies had evaluated the filling ability of this material with the intent of comparing the results of the technique proposed by the manufacturer (single-cone technique) with cold lateral compaction. The latter is considered the conventional technique against which all other techniques should be compared. ${ }^{24}$ Nonetheless, during cold lateral compaction, the repeated introduction of spreaders into the canal exerts mechanical stress onto the root canal walls, increasing the risk of fracture. ${ }^{25,26}$ For this reason, the use of cold lateral compaction has recently been questioned.

The findings from the present study are in agreement with several studies using traditional sealers, which also reported favorable results for the single-cone technique in terms of its filling ability. This was observed not only in circular canals ${ }^{27-29}$ but also in oval canals. ${ }^{4,11}$ The results from these studies are comparable to studies evaluating other obturation techniques, such as the continuous wave of compaction, ${ }^{28}$ cold lateral compaction, ${ }^{27,29}$ and Thermafil. 29

Compared with an earlier study, ${ }^{11}$ the present study found a greater percentage of voids in the apical portion of the canal when obturation was performed with a single cone. While the present study observed $13 \%$ of voids in the apical portion of the canal, the previous one observed only $0.02 \%$. Although both of these studies were conducted in premolars with oval canals and used the same evaluation method (micro-CT), differences regarding sample size, tooth selection and paring, apical preparation diameters, the methodology for voids assessment, and time to complete the sealer setting could justify this discrepancy.

In the present study, the volume of voids was greater in the coronal portion of the canal, which is probably due to the tendency to the canals toward a rounder shape closer to the apex, and to the fit of the cone in this portion. ${ }^{30}$ Still, none of the obturation techniques was capable of filling the root canal space completely in all specimens, which corroborates previous studies involving micro-CT analyses in oval root canals. ${ }^{11,31}$

Oval canals are regarded as the best model to evaluate the filling ability of different obturation techniques. ${ }^{32}$ Voids are more common in this type of canal than in circular canals, not only due to the limitations of the obturation techniques but also due to the presence of unprepared areas, especially in buccal and lingual recesses. ${ }^{33-35}$ The risk of treatment failure may be higher when the filling material is unable to trap the bacteria left in these areas. ${ }^{36,37}$ Hence, the development of new materials and techniques to fill oval canal recesses should be encouraged.

One must be cautious when extrapolating the present findings into the clinical reality, considering the limitations inherent to ex vivo studies and the fact that the obturation quality was evaluated at a specific moment in time. For this reason, it is impossible to speculate whether the quality of these obturations will be maintained over time.

\section{Conclusions}

The quality of the fillings produced by the single-cone technique was similar to the cold lateral compaction using EndoSequence BC sealer in oval canals. Other current obturation techniques combined with other bioceramic sealers should be further compared.

\section{Funding}

This study was supported by grants from Fundação de Amparo à Pesquisa do Estado do Rio de Janeiro (FAPERJ), Brazilian Governmental Institution.

\section{Conflict of Interest}

None declared.

\section{References}

1 Gillen BM, Looney SW, Gu LS, et al. Impact of the quality of coronal restoration versus the quality of root canal fillings on success of root canal treatment: a systematic review and meta-analysis. J Endod 2011;37(7):895-902

2 Hussein FE, Liew AK, Ramlee RA, Abdullah D, Chong BS. Factors associated with apical periodontitis: a multilevel analysis. J Endod 2016;42(10):1441-1445

3 Brosco VH, Bernardineli N, Torres SA, et al. Bacterial leakage in obturated root canals-part 2: a comparative histologic and microbiologic analyses. Oral Surg Oral Med Oral Pathol Oral Radiol Endod 2010;109(5):788-794

4 Wu MK, Ozok AR, Wesselink PR. Sealer distribution in root canals obturated by three techniques. Int Endod J 2000;33(4): 340-345

5 Yücel AC, Ciftçi A. Effects of different root canal obturation techniques on bacterial penetration. Oral Surg Oral Med Oral Pathol Oral Radiol Endod 2006;102(4):e88-e92

6 Trope M, Bunes A, Debelian G. Root filling materials and techniques: bioceramics a new hope? Endod Topics 2015;32:86-96

7 Zhou HM, Shen Y, Zheng W, Li L, Zheng YF, Haapasalo M. Physical properties of 5 root canal sealers. J Endod 2013;39(10): 1281-1286

8 Chybowski EA, Glickman GN, Patel Y, Fleury A, Solomon E, He J. Clinical outcome of non-surgical root canal treatment using a single-cone technique with endosequence bioceramic sealer: a retrospective analysis. J Endod 2018;44(6):941-945

9 Wang Z, Shen Y, Haapasalo M. Dentin extends the antibacterial effect of endodontic sealers against Enterococcus faecalis biofilms. J Endod 2014;40(4):505-508

10 Rodríguez-Lozano FJ, García-Bernal D, Oñate-Sánchez RE, Ortolani-Seltenerich PS, Forner L, Moraleda JM. Evaluation of cytocompatibility of calcium silicate-based endodontic sealers and their effects on the biological responses of mesenchymal dental stem cells. Int Endod J 2017;50(1):67-76

11 Celikten B, Uzuntas CF, Orhan AI, et al. Evaluation of root canal sealer filling quality using a single-cone technique in oval shaped canals: an in vitro Micro-CT study. Scanning 2016; 38(2):133-140

12 Pawar AM, Pawar S, Kfir A, Pawar M, Kokate S. Push-out bond strength of root fillings made with C-Point and $B C$ sealer versus gutta-percha and AH Plus after the instrumentation of oval canals with the Self-Adjusting File versus WaveOne. Int Endod J 2016;49(4):374-381

13 Loushine BA, Bryan TE, Looney SW, et al. Setting properties and cytotoxicity evaluation of a premixed bioceramic root canal sealer. J Endod 2011;37(5):673-677 
14 De-Deus G, Reis C, Beznos D. de Abranches AM, Coutinho-Filho T, Paciornik S. Limited ability of three commonly used thermoplasticized gutta-percha techniques in filling oval-shaped canals. J Endod 2008;34(11):1401-1405

15 Jou YT, Karabucak B, Levin J, Liu D. Endodontic working width: current concepts and techniques. Dent Clin North Am 2004;48(1):323-335

16 Siqueira JF Jr, Magalhães KM, Rôças IN. Bacterial reduction in infected root canals treated with $2.5 \% \mathrm{NaOCl}$ as an irrigant and calcium hydroxide/camphorated paramonochlorophenol paste as an intracanal dressing. J Endod 2007;33(6):667-672

17 Versiani MA, Alves FR, Andrade-Junior CV, et al. Micro-CT evaluation of the efficacy of hard-tissue removal from the root canal and isthmus area by positive and negative pressure irrigation systems. Int Endod J 2016;49(11):1079-1087

18 Seltzer S, Endodontology. Biologic Considerations in Endodontic Procedures. 2nd edition. Philadelphia: Lea \& Febiger; 1988: 365-366

19 Wu MK, van der Sluis LW, Wesselink PR. A 1-year follow-up study on leakage of single-cone fillings with RoekoRSA sealer. Oral Surg Oral Med Oral Pathol Oral Radiol Endod 2006; 101(5):662-667

20 Shokouhinejad N, Gorjestani H, Nasseh AA, Hoseini A, Mohammadi M, Shamshiri AR. Push-out bond strength of gutta-percha with a new bioceramic sealer in the presence or absence of smear layer. Aust Endod J 2013;39(3):102-106

21 Candeiro GT, Correia FC, Duarte MA, Ribeiro-Siqueira DC, Gavini G. Evaluation of radiopacity, pH, release of calcium ions, and flow of a bioceramic root canal sealer. J Endod 2012;38(6):842-845

22 Sarkar NK, Caicedo R, Ritwik P, Moiseyeva R, Kawashima I. Physicochemical basis of the biologic properties of mineral trioxide aggregate. J Endod 2005;31(2):97-100

23 Silva Almeida LH, Moraes RR, Morgental RD, Pappen FG. Are premixed calcium silicate-based endodontic sealers comparable to conventional materials? a systematic review of in vitro studies. J Endod 2017;43(4):527-535

24 Wu MK, Bud MG, Wesselink PR. The quality of single cone and laterally compacted gutta-percha fillings in small and curved root canals as evidenced by bidirectional radiographs and fluid transport measurements. Oral Surg Oral Med Oral Pathol Oral Radiol Endod 2009;108(6):946-951

25 Meister F Jr, Lommel TJ, Gerstein H. Diagnosis and possible causes of vertical root fractures. Oral Surg Oral Med Oral Pathol 1980;49(3):243-253
26 Schmidt KJ, Walker TL, Johnson JD, Nicoll BK. Comparison of nickel-titanium and stainless-steel spreader penetration and accessory cone fit in curved canals. J Endod 2000;26(1):42-44

27 Gordon MP, Love RM, Chandler NP. An evaluation of. 06 tapered gutta-percha cones for filling of. 06 taper prepared curved root canals. Int Endod J 2005;38(2):87-96

28 Cavenago BC, Duarte MA, Ordinola-Zapata R, Marciano MA, Carpio-Perochena $\mathrm{AE}$, Bramante $\mathrm{CM}$. Interfacial adaptation of an epoxy-resin sealer and a self-etch sealer to root canal dentin using the System B or the single cone technique. Braz Dent J 2012;23(3):205-211

29 Inan U, Aydin C, Tunca YM, Basak F. In vitro evaluation of matched-taper single-cone obturation with a fluid filtration method. J Can Dent Assoc 2009;75(2):123

30 Wu MK, R'oris A, Barkis D, Wesselink PR. Prevalence and extent of long oval canals in the apical third. Oral Surg Oral Med Oral Pathol Oral Radiol Endod 2000;89(6):739-743

31 Keles A, Alcin H, Kamalak A, Versiani MA. Micro-CT evaluation of root filling quality in oval-shaped canals. Int Endod J 2014;47(12):1177-1184

32 Jarrett IS, Marx D, Covey D, Karmazin M, Lavin M, Gound T. Percentage of canals filled in apical cross sections - an in vitro study of seven obturation techniques. Int Endod J 2004;37(6):392-398

33 Versiani MA, Pécora JD, de Sousa-Neto MD. Flat-oval root canal preparation with self-adjusting file instrument: a micro-computed tomography study. J Endod 2011;37(7): 1002-1007

$34 \mathrm{Wu} \mathrm{MK}$, Wesselink PR. A primary observation on the preparation and obturation of oval canals. Int Endod J 2001;34(2): 137-141

35 Siqueira JF Jr, Pérez AR, Marceliano-Alves MF, et al. What happens to unprepared root canal walls: a correlative analysis using micro-computed tomography and histology/scanning electron microscopy. Int Endod J 2018;51(5):501-508

36 Ricucci D, Siqueira JF Jr, Bate AL, Pitt Ford TR. Histologic investigation of root canal-treated teeth with apical periodontitis: a retrospective study from twenty-four patients. J Endod 2009;35(4):493-502

37 Torabinejad M, Ung B, Kettering JD. In vitro bacterial penetration of coronally unsealed endodontically treated teeth. J Endod 1990;16(12):566-569 